\title{
TRAO ĐỐI
}

\section{ĐÔI NÉT VỀ DỊCH VÀ PHƯƠNG PHÁP DẠY BIÊN DỊCH HÂN VIỆT CHO LƯU HỌC SINH TRUNG QUỐC Ở VIỆT NAM}

\author{
Phạm Ngọc Hàm* \\ Truòng Đại học Ngoại ngũ, ĐHQGHN \\ Phạm Văn Đồng, Cầu Giấy, Hà Nội, Việt Nam
}

Nhận bài ngày 02 tháng 05 năm 2019

Chỉnh sửa ngày 14 tháng 06 năm 2019; Chấp nhận đăng ngày 26 tháng 09 năm 2019

Tóm tắt: Dịch có thể coi là một trong những kỹ năng thực hành ngôn ngữ mang tính tổng hợp, đòi hỏi người dạy và người học cùng một lúc vận dụng kiến thức trên tất cả các bình diện, nhất là từ vựng và ngữ pháp cũng như giao văn hóa vào việc tìm ra cách biểu đạt tương đương trong ngôn ngữ đích so với văn bản nguồn. Trên cơ sở khái quát một số vấn đề lý luận về dịch và phương pháp dạy học dịch, kết hợp với thực tế dạy học biên dịch cho lưu học sinh Trung Quốc ở một số trường đại học tại Việt Nam, bài viết vận dụng phương pháp phân tích, so sánh đối chiếu thảo luận về phương pháp xử lí từ và câu trong biên dịch và dạy học dịch, từ đó đưa ra kiến nghị nhằm nâng cao chất lượng dạy học môn Biên dịch Hán Việt cho lưu học sinh Trung Quốc ở Việt Nam.

Tù khóa: Dịch Hán Việt; dạy học; sinh viên Trung Quốc; kiến nghị

\section{1. Đặt vấn đề}

Từ khi thực hiện chính sách cải cách mở cửa đến nay, cùng với quá trình giao lưu quốc tế ngày càng mở rộng và đi vào chiều sâu, quan hệ hợp tác giữa hai nước Việt Trung cũng được nâng lên những tầm cao mới. Dạy học tiếng Trung Quốc cho người Việt Nam và tiếng Việt cho người Trung Quốc như một ngoại ngữ ngày càng phát triển cả về lượng và chất. Hằng năm, Trường Đại học Khoa học Xã hội \& Nhân văn và Trường Đại học Ngoại ngữ, Đại học Quốc gia Hà Nội tiếp nhận hàng trăm sinh viên từ các trường đại học của Trung Quốc đến học tập và nâng cao trình độ tiếng Việt. Môn dịch, trong đó có dịch nói và dịch viết, là một trong những môn học quan

ĐT.: 84-904123803

Email: phamngochamnnvhtq@gmail.com trọng, thiết thực được đông đảo sinh viên đón nhận. Ở Việt Nam hiện nay, nghiên cứu về giảng dạy dịch cho đối tượng là sinh viên Việt Nam bao gồm đối dịch Việt Anh, Việt Trung, Việt Nga, Việt Pháp,... đã và đang được quan tâm, nhưng dạy dịch cho sinh viên nước ngoài tại Việt Nam, trong đó có lưu học sinh Trung Quốc chưa nhận được sự quan tâm cần thiết của giới nghiên cứu. Trong khuôn khổ bài viết này, trên cơ sở khái quát một số vấn đề lý luận và thực tiễn về dịch và phương pháp dạy dịch nói chung cũng như dạy biên dịch cho lưu học sinh Trung Quốc ở Việt Nam nói riêng, chúng tôi tiến hành phân tích một số phương pháp xử lý từ và câu trong dạy học dịch, từ đó đưa ra kiến nghị nhằm cải tiến và nâng cao chất lượng dạy học, trước hết là môn Biên dịch Hán Việt cho lưu học sinh Trung Quốc ở Việt Nam. 


\section{2. Đôi nét về dịch và dạy dịch}

Về khái niệm phiên dịch, Tù điển quy pham tiếng Hán hiện đại (现代汉语规范词典) giải thích rằng, "phiên dịch" là động từ chỉ hành vi biểu đạt ngôn ngữ văn tự này bằng một ngôn ngữ văn tự khác; biểu đạt ký hiệu hoặc mã số tiêu biểu cho ngôn ngữ văn tự bằng một ngôn ngữ văn tự khác (把某种语言 文字用另 一 种语言文字表达出来; 把代表语言 文字的符号或数码用语言文字表达出来）（李宝 嘉、唐志超 Lý Bảo Gia, Đuòng Hán Siêu, 2001). Tuy nhiên, theo chúng tôi, dịch là một hành vi ngôn ngữ nhằm truyền đạt một thông tin nào đó từ ngôn bản nguồn sang ngôn bản đích. Ngôn bản ấy có thể là một câu, một đoạn văn hay một văn bản hoàn chỉnh. Mỗi ngôn ngữ đều có những đặc điểm về ngữ âm, văn tự, từ vựng và ngữ pháp riêng, do đó, trong quá trình chuyển dịch từ ngôn bản nguồn sang ngôn bản đích không thể có được sự tương ứng hoàn toàn. Không những thế, nhân tố văn hóa dân tộc cũng ảnh hưởng sâu sắc đến quá trình chuyển dịch. Một bản dịch tiêu chuẩn cần đạt được sự tương đồng cả về ngôn ngữ và văn hóa, đồng thời thể hiện chính xác ý nghĩa ngữ dụng cũng như thể loại văn bản của ngôn bản đích so với ngôn bản nguồn. Vì vậy, trong quá trình chuyển dịch, "người dịch cần cố gắng sao cho ý định của tác giả ngôn bản nguồn phù hợp với sự mong đợi của người đọc bản dịch. Muốn làm được điều đó, người dịch trước hết phải thông qua những đầu mối giao tiếp thể hiện trên các phương diện như ngữ âm, cú pháp, ngữ nghĩa, ngữ dụng, thể tài của ngôn bản nguồn để thể hiện đúng ý đồ giao tiếp của tác giả, sau đó căn cứ vào ngữ cảnh tiềm tàng hoặc môi trường nhận thức của người đọc bản dịch, chọn trong những đáp án có liên quan một hình thức biểu đạt tốt nhất.” (译者应尽量 使原文作者的意图与译文读者的期待相符。要做到 这一点, 译者必须先通过原文的语音、句法、语 义、语用、文体等各层面的交际线索体察出作者的 交际意图, 然后根据译文读者的潜在语境或认识环
境, 在有关联的数个答案中选取关联性最佳的那一 个) (胡悦芝 Hồ Duyệt Chi, 2013). Có thể nói, người dịch đóng vai trò cầu nối giữa ngôn bản nguồn và ngôn bản đích, đòi hỏi phải có hiểu biết đầy đủ về các tri thức ngôn ngữ và văn hóa cần thiết để hiểu đúng tinh thần ngôn bản nguồn và các tri thức ngôn ngữ, văn hóa liên quan đến ngôn bản đích, mới có thể chuyển tải được đầy đủ ý tưởng của tác giả thể hiện trong ngôn bản nguồn.

Căn cứ vào đặc điểm, tính chất và hình thức của hành động dịch, người ta có thể chia dịch thành dịch nói, còn gọi là phiên dịch và dịch viết, còn gọi là biên dịch. Về phương pháp, có thể chia thành dịch âm, dịch nghĩa, kết hợp âm và nghĩa. Ngoài ra, căn cứ vào mục đích nắm bắt thông tin, còn có thể chia thành dịch toàn văn và lược dịch. Biên dịch là hình thức dịch dựa trên ngôn bản viết có sẵn, đòi hỏi người dịch ngoài việc nắm bắt được các kỹ năng về dịch thuật nói chung ra, còn phải thông hiểu về văn bản học, có kỹ năng lí giải văn bản, xử lý từ và câu một cách linh hoạt. Đối với một văn bản viết, câu hoặc đoạn văn trên dưới chính là ngữ cảnh giúp cho việc xác định chính xác nghĩa của từ, thậm chí là của câu. Vì vậy, phân tích ngôn cảnh là khâu vô cùng quan trọng giúp người dịch tìm ra được tương quan trong biểu đạt giữa bản nguồn và bản dịch. "Phân tích ngôn cảnh là hình dung ra hoàn cảnh, môi trường trong đó ngôn bản được tạo ra.” (Đinh Hồng Vân, 2016). Phân tích ngôn cảnh tạo tiền đề cho người dịch "tìm được trong ngôn ngữ dịch những phương tiện biểu đạt tối ưu, phù hợp với thói quen ngôn ngữ của người tiếp nhận bản dịch." (Đinh Hồng Vân, 2016).

Xét về mặt dạy học ngoại ngữ, dịch là kỹ năng thực hành tổng hợp, kết hợp giữa nghe, nói, đọc và viết. Trong đó, dịch nói cần nghiêng về trau dồi và rèn luyện kỹ năng nghe và nói nhiều hơn; dịch viết cần nghiêng về kỹ 
năng đọc hiểu ngôn bản nguồn và diễn đạt viết trong ngôn bản đích.

Trong hai học kỳ của năm học thứ ba, cũng là năm học chuyển tiếp của sinh viên Trung Quốc chuyên ngành tiếng Việt tại Trường Đại học Khoa học Xã hội \& Nhân văn, các em được tiếp xúc với môn Lý luận và Thực hành biên dịch Hán Việt trong thời lượng 120 tiết học, mỗi tuần 4 tiết. Chương trình môn dịch cho lớp chuyển tiếp lưu học sinh Trung Quốc của Trường Đại học Ngoại ngũ̃, Đại học Quốc gia Hà Nội gồm 240 tiết, chia thành thực hành dịch nói (phiên dịch) và thực hành dịch viết (biên dịch), mỗi kỹ năng 4 tiết/ tuần. Những sinh viên này chủ yếu đến từ Khoa Tiếng Việt của các trường như Đại học Vân Nam, Đại học Dân tộc Quảng Tây Trung Quốc, các em đã hoàn thành hai năm học đầu, đạt trình độ tiếng Việt Trung cấp. Trong khuôn khổ bài viết này, chúng tôi chủ yếu tập trung vào đối tượng là các lớp Lưu học sinh Trung Quốc theo học biên dịch ở Trường Đại học Khoa học Xã hội \& Nhân văn, Đại học Quốc gia Hà Nội, nơi mà người viết đã trực tiếp giảng dạy môn học này với tư cách giáo viên thỉnh giảng. Vì tên gọi môn học là Lý luận và Thực hành biên dịch nên đòi hỏi trong quá trình dạy học, giáo viên cần kết hợp lý luận với thực tiễn để gợi mở cho sinh viên hiểu được phương thức chuyển dịch như thế nào, nói như tiếng Trung Quốc là 知其然tri kỳ nhiên, tiến thêm một bước hiểu được tại sao lại chuyển dịch như thế, nói như tiếng Trung Quốc là 知其所以然tri kỳ sở dĩ nhiên. Như vậy giáo viên sẽ phát huy được mối liên hệ giữa lý thuyết và thực hành, giúp sinh viên từ thực tiễn rút ra quy tắc chuyển dịch, đồng thời thực hành dịch dưới ánh sáng của cơ sở lý luận. Để đạt được hiệu quả cao trong quá trình dạy học, giáo viên cần làm chủ được cả về lý thuyết và thực hành dịch, chuyển hóa linh hoạt giữa lý thuyết và kỹ năng để hướng đạo cho sinh viên từ lý luận đến vận dụng và từ vận dụng đến củng cố kiến thức lý thuyết.
Việc dạy học biên dịch cho lưu học sinh Trung Quốc cũng phải tuân thủ các nguyên tắc của dạy học ngoại ngữ nói chung, như tinh giảng, đa luyện. Đối với môn dịch thì cái gọi là tinh giảng ở đây là những vấn đề lý thuyết cần được nêu ra một cách cô đọng nhất, cơ bản nhất, chưa cần đến mức hàn lâm, dành thời gian tối đa cho thực hành.

Trong quá trình hướng đạo cho sinh viên trên lớp, cần thông qua việc thiết kế loạt câu hỏi mang tính chất gợi mở, ưu tiên cho hai cấp bậc, bậc một là nhur thế nào? Bậc hai là tại sao? Xuất phát từ tính chất của khẩu ngữ và bút ngữ, diễn đạt nói và diễn đạt viết cũng như dịch nói và dịch viết là khác nhau, nhưng giữa chúng lại có mối liên hệ mật thiết với nhau, giáo viên cần thông qua hệ thống câu hỏi gợi mở để hướng dẫn sinh viên thực hiện các bước biên dịch, cụ thể gồm: (1) tìm hiểu ngôn bản nguồn; (2) xác định điểm khó trong câu để trên cơ sở đó tìm ra các đường hướng xử lý từ và câu. Khi thực hiện một bài giảng về lý luận và thực hành biên dịch, giáo viên có thể sử dụng phương pháp diễn dịch hoặc quy nạp, cũng có thể kết hợp giữa diễn dịch và quy nạp trong cùng một bài giảng. Đồng thời, có thể vận dụng phương thức thông qua hỏi đáp giữa thầy và trò, giúp cho sinh viên giải quyết được các trở ngại về ngôn ngữ và văn hóa, sau đó tiến hành dịch viết trên giấy. Tùy vào độ dài của từng bài, giáo viên có thể tách thành đoạn và chỉ định một sinh viên viết đáp án của mình lên bảng, tận dụng bài viết của sinh viên trên bảng làm ví dụ trực quan hướng dẫn cả lớp thông qua quan sát tìm ra ưu, nhược điểm trong đoạn dịch của bạn, chỉ ra lỗi sai và tiến hành sửa lỗi. Đối với những câu tuy không có lỗi nhưng cách dùng từ hoặc xử lý câu chưa thật tốt, cần gợi mở cho sinh viên tìm ra những cách dịch phù hợp hơn. Cuối cùng, giáo viên đưa ra lời dịch của mình để sinh viên tham khảo. Phương thức thứ hai, giáo viên có thể thông qua hình thức vấn đáp, gợi mở cho 
sinh viên trên cơ sở xử lý từ và câu, trước hết tiến hành dịch miệng, rồi sau đó mới bước vào dịch viết.

Trong một văn bản thường có những câu khó, từ khó đan xen với những câu đơn giản. Trên lớp giáo viên có thể bỏ qua các câu đơn giản, nhưng cũng có thể tận dụng những câu đó để yêu cầu những sinh viên năng lực còn có những hạn chế nhất định đưa ra đáp án, nhằm cuốn hút đối tượng này tham gia vào giờ học, xây dựng niềm tin có thể học được cho những sinh viên yếu kém hơn trong lớp. Trên cơ sở thực hành dịch miệng, bước tiếp theo cho sinh viên thực hành dịch viết trên giấy. Với phương thức này, giáo viên cũng nên chỉ định một em lên trình bày bài trên bảng, coi đó là ví dụ cụ thể để cả lớp cùng tiến hành phân tích, đánh giá và chỉnh sửa trên mọi phương diện gồm từ, ngữ pháp, nội dung, hình thức và lỗi chính tả. Để tận dụng thời gian và vai trò của giáo viên trên lớp, trong khi sinh viên thực hành dịch viết trên giấy, giáo viên có thể đi dọc theo hàng ghế để quan sát và chữa bài cho từng sinh viên, từ đó nắm được năng lực của từng em, đồng thời củng cố quan hệ thầy và trò trong mỗi giờ học.

\section{Một số lỗi sinh viên Trung Quốc thường gặp trong học tập môn Biên dịch Hán Việt}

Qua thực tế nhiều năm dạy học dịch Hán Việt cho lưu học sinh Trung Quốc tại Trường Đại học Khoa học Xã hội \& Nhân văn, Đại học Quốc gia Hà Nội, chúng tôi đã tổng kết lại một số lỗi thường gặp của đối tượng người học này thể hiện trên các phương diện như lỗi về mặt tái hiện từ ngữ trong văn bản viết, bao gồm cả về phụ âm, phần vần và thanh điệu. Lỗi về mặt sử dụng từ ngữ chủ yếu thể hiện ở việc suy luận từ cách đọc Hán Việt. Các em chưa nhận thức được một cách đầy đủ rằng, mặc dù trong tiếng Việt có đến trên $60 \%$ từ Việt gốc Hán được tiếp nhận qua quá trình tiếp xúc Hán Việt, nhưng khi gia nhập hệ thống từ vựng tiếng Việt, lớp từ Việt gốc Hán này phân hóa theo các xu hướng như (1) giữ nguyên từ loại, nghĩa và cách dùng, như生长sinh trương, 教育 giáo duc, 事业 sụ nghiệp...; (2) có sự thay đổi về từ loại, chẳng hạn như 特色đăc sắc, 兴趣 hưng thú, 心得 tâm đắc trong tiếng Hán là danh từ, sang tiếng Việt đều chuyển hóa thành tính từ hoặc động từ chỉ hoạt động tâm lý; (3) có sự thay đổi về nghĩa, hoặc thu hẹp, hoặc mở rộng, hoặc thay đổi về sắc thái, ví dụ 手段 thủ đoạn trong tiếng Hán là từ trung tính, nghĩa là thủ pháp, biện pháp. Trong tiếng Việt, thủ đoạn lại có nghĩa là âm mưu, toan tính xấu xa; (4) có sự thay đổi về trật tự từ, như 答复đáp phúc成长 thành trương tiếng Hán, sang tiếng Việt trật tự từ trái ngược, lần lượt là phúc đáp, truoơng thành. Ngoài ra, trong tiếng Việt còn có một loạt các từ mà người Việt tự tạo dựa trên các yếu tố gốc Hán nhưng không có trong tiếng Hán, nhằm đáp ứng nhu cầu giao tiếp, khiến cho vốn từ tiếng Việt ngày càng phong phú đa dạng, chẳng hạn như nhà báo, phóng viên, hội đồng... Đối với sinh viên Trung Quốc học tiếng Việt cũng như sinh viên Việt Nam học tiếng Hán, từ Hán Việt như một “con dao hai lưỡi”, vừa giúp ích cho việc học từ đơn, vừa là một trong những nguyên nhân gây nên lỗi do lạm dụng cách đọc Hán Việt để suy đoán nghĩa của từ.

Lỗi về mặt ngữ pháp mà lưu học sinh Trung Quốc thường gặp là lỗi về định ngữ, trạng ngữ, chủ yếu do trật tự từ trong cấu trúc định ngữ nối kết với trung tâm ngữ và vị trí thành phần trạng ngữ trong câu tiếng Hán và câu tiếng Việt có khác nhau. Một khi sinh viên chịu ảnh hưởng của sự chuyển di tiêu cực từ tiếng mẹ đẻ sang ngôn ngữ đích sẽ dễ dàng mắc lỗi, đặc biệt là về thành phần trạng ngữ, trong tiếng Hán, trạng ngữ bổ nghĩa cho toàn câu thường đứng ở đầu câu hoặc sau chủ ngữ, trạng ngữ bổ nghĩa cho động từ thì luôn luôn đứng trước động từ, trong khi vị trí trạng ngữ của câu tiếng Việt khá linh hoạt, có thể đứng 
ở đầu câu, sau chủ ngữ hoặc cuối câu. Tuy nhiên, với mỗi vị trí khác nhau thì sắc thái nghĩa và trọng điểm cần nhấn mạnh cũng khác nhau. Ví dụ, Một cách tình tứ, Chí ngẩng lên nhì Thị (Chí Phèo: Nam Cao), câu này có thể biểu đạt bằng những cách khác như: (1) Chi ngẩng lên nhìn thị (một cách) tình tứ; (2) Chi tình tứ ngẩng lên nhì Thị. Trong nguyên văn tác phẩm, Nam Cao đưa thành phần trạng ngữ một cách tình tư đặt lên trước chủ ngữ là có dụng ý khắc sâu dáng vẻ hiền hậu, đáng yêu của Chí Phèo khi tỏ tình với Thị Nở, khiến độc giả liên hệ đến vẻ hung dữ, côn đồ của Chí trước đó mà nhận thức được rằng, $C h i$ cũng là con người có trái tim biết yêu thuoong nhu bao nhiêu nguoời khác. Trên thực tế, khi chuyển dịch câu này sang tiếng Hán, sinh viên Trung Quốc sẽ không thể chủ động đưa ra cách dịch phù hợp nhất mà thông thường sẽ mô phỏng mẫu câu thường gặp trong tiếng Hán để chuyển dịch thành 志漂以爱情的目光 看着氏女 (Chí nhìn Thị với ánh mắt của tình yêu). Đương nhiên, cách dịch này cũng rất sáng tạo và chấp nhận được, song nhìn chung, sinh viên Trung Quốc chưa thể đưa ra các cách biểu đạt tương đương khác, chẳng hạn 志 漂充满情意地望着氏女. Đặc biệt là trong trường hợp dịch từ tiếng Hán sang tiếng Việt, các cách chuyển dịch linh hoạt, nhất là vận dụng phương thức đảo ngữ để làm nổi bật hình ảnh cần nhấn mạnh như ví dụ trên đây thì quả là “điều xa xî" với sinh viên.

Ngoài ra, còn có những lỗi do sự khác biệt về văn hóa trong ngôn ngữ, thể hiện rõ nét nhất là sự chênh lệch trong tri nhận ẩn dụ gây ra, chẳng hạn như thành ngữ 嫁鸡随鸡, 嫁狗随狗 giá kê tùy kê, giá cẩu tùy cẩu trong tiếng Hán tương đương với thuyền theo lái, gái theo chồng trong tiếng Việt; hay như sự chênh lệch trong cách biểu đạt con số của các thành ngữ có yếu tố con số, như 九死一生cưu tử nhất sinh, 三妻四妾tam thê tư thiếp, 五颜六色 ngũ nhan lục sắc trong tiếng Hán, sang tiếng
Việt lần lượt chuyển thành thập tử nhất sinh, năm thê bảy thiếp, muôn màu muôn sắc... Lỗi về hình thức văn bản chủ yếu thể hiện ở hình thức trình bày do sự khác nhau trong quy cách văn bản, nhất là thư từ trong hai ngôn ngữ. Nguyên nhân mắc lỗi cũng xuất phát từ thói quen sử dụng ngôn ngữ và trình bày văn bản của tiếng mẹ đẻ.

\section{Phương pháp giảng dạy}

\subsection{Nhũng nguyên tắc chung}

Để thực hiện tốt một giờ dạy biên dịch cho lưu học sinh Trung Quốc, chúng ta cần tuân thủ nguyên tắc chung của dạy học ngoại ngữ như lấy người học làm trung tâm, giáo viên là người hướng đạo, nguyên tắc từ dễ đến khó, từ đơn giản đến phức tạp, vận dụng thành quả so sánh đối chiếu ngôn ngữ Hán Việt trong dạy dịch. Giáo viên cần nắm được đặc điểm tâm lý và trình độ của từng sinh viên để có những động viên kịp thời với những em tiếp thu chưa thật tốt. Mặt khác, trong thực tế dịch thuật, đôi khi người dịch chưa thể hoặc chưa kịp tìm ra phương thức biểu đạt phù hợp nhất, tính có thể chấp nhận trong chuyển dịch ngôn ngữ vẫn có thể cho phép lựa chọn và công nhận phương án biểu đạt tiếp cận chuẩn mực, tức là phương án chuyển dịch tuy đã truyền đạt được những thông tin cơ bản của nguyên bản, nhưng còn hạn chế nhất định về mặt hình thức ngôn ngữ hoặc nội dung. Trong quá trình dạy học dịch, giáo viên càng cần phải quán triệt tinh thần này để từng bước nâng cao trình độ và củng cố niềm tin "có thể học được" cho sinh viên, từ đó thu hút và khuyến khích tất cả các thành viên ở các trình độ khác nhau vào hoạt động dạy học trên lớp.

\subsection{Phương pháp xử lý tù̀}

Trong tiến trình bài giảng, trước hết, giáo viên cần hướng dẫn sinh viên lí giải ý nghĩa của từ trong ngôn bản nguồn. Trong đó, cần 
phát huy vai trò của yếu tố ngữ cảnh để xác định nghĩa của từ, đồng thời vận dụng phương pháp thay thế từ đồng nghĩa, gần nghĩa để tìm ra từ tương đương, nhất là trường hợp người dịch chưa từng gặp từ ngữ xuất hiện trong bản nguồn, nhưng căn cứ vào vốn từ vựng được tích lũy và dựa vào ngữ cảnh, có thể tìm ra từ tương đương có thể thay thế cho từ cần chuyển dịch từ ngôn bản nguồn. Việc tận dụng vai trò của ngữ cảnh để chuyển dịch trước hết thể hiện ở chỗ đặt từ vào trong đơn vị giao tiếp nhỏ nhất là câu để xác định nghĩa, nói cách khác là lấy câu làm đơn vị dịch, và tìm ra cách cách biểu đạt tương đương. Sau khi đưa ra các phương án chuyển dịch khác nhau, giáo viên cần hướng dẫn cho sinh viên thông qua so sánh, tìm ra đáp án tối ưu. Chẳng hạn, khi chuyển dịch câu “他现在要将这包里的 新生命, 移植到他家里, 收获许多幸福”(Lố Tấn: “Thuốc") sang tiếng Việt, trong quá trình tìm hiểu câu văn này, giáo viên cần gợi mở cho sinh viên nhớ lại tác phẩm "Thuốc" của Lỗ Tấn, từ đó yêu cầu sinh viên tìm ra thủ pháp tu từ trong câu, hoặc nhấn vào các từ “新生命 tân sinh mệnh", “移植 di thưc" và “收获 thu hoạch", yêu cầu sinh viên tìm ra mối tương quan giữa các từ ngữ đó. Một khi người dịch có thể lĩnh hội được mối liên hệ giữa sự sống hồi sinh trên cơ thể bé Thuyên, rồi bé Thuyên sẽ trưởng thành trong niềm hy vọng của ông Thuyên với quá trình ươm mầm non, chờ đơm hoa kết trái và thu hoạch, sẽ đưa ra được đáp án tối ưu là bây giờ, lão phải đem mầm sống mới này về ươm tại nhà mình, gặt hái bao hạh phúc. Thành công của phương án dịch này là ở chố, người dịch đã tìm ra mối tương quan giữa ba cụm từ 新生命 tân $\sinh m e \hat{n} h$ (mạng sống mới), 移植到他家 di thực đáo tha gia (chuyển về trồng ở nhà ông ấy) và 收获 thu hoạch trong câu văn cũng như trong bối cảnh của toàn tác phẩm, qua đó tiến thêm một bước "nâng cấp" ngôn từ, chuyển hóa mạng sống mới thành mầm sống mới; chuyển về trồng ở nhà ông ấy thành về urom tại nhà mình và thu hoạch chuyển hóa thành gặt hái. Lời dịch vừa đảm bảo truyền đạt được đúng và đầy đủ nội dung của ngôn bản nguồn, vừa thể hiện được đầy đủ ý nghĩa của thủ pháp tu từ mà Lỗ Tấn sử dụng trong câu văn. Có thể nói, cách dịch này cũng mang sắc thái riêng, bám sát tinh thần ngôn bản nguồn, không kém gì so với lời dịch của Trương Chính Lão sẽ mang cái gói này về nhà, đem sinh mệnh lại cho con lão, và lão sung sương biết bao!

Một ví dụ khác, trong bài 徐悲鸿Tù $B i$ Hồng có câu 他如饥似渴地从这些作品中吸取了 营养. Câu văn diễn tả niềm đam mê, say sưa học hỏi, tiếp thu tri thức hội họa phương Tây của Từ Bi Hồng khi được sang Pháp tiếp xúc với các tác phẩm hội họa của các danh họa bản địa. Tác giả đã sử dụng hình ảnh so sánh 如饥似渴 nhu co tụ khát (như đói như khát), 吸取 hấp thủ (hút lấy), 营养 dinh duõng làm tăng thêm tính hình tượng của câu văn. Nếu chỉ căn cứ vào nghĩa liệt kê trong từ điển mà chuyển dịch sang tiếng Việt thì câu văn sẽ không thể nhận được sự đồng thuận của độc giả người Việt, bởi vì nhu đói nhu khát là lối ví von mang tính tiêu cực, hấp thu dinh dương trong tiếng Việt chỉ dùng trong sinh học, chỉ quá trình sinh trưởng của động, thực vật. Vì vậy, người giáo viên cần gợi mở cho sinh viên nắm được mối tương quan giữa tác phẩm hộ họ, tiếp thu và dinh duỡng, đồng thời tìm ra ý nghĩa ẩn dụ của câu văn này là nỗi khát khao cháy bỏng và niềm vui vô bờ. Một phương án gợi mở rất lý thú là dẫn ra bài thơ Nhân sinh tú hỷ của Uông Châu（汪洙: 人生四喜）久旱逢 甘雨, 他乡遇故知, 洞房花烛夜, 金榜题名时 $c u u$ hạn phùng cam vũ, tha huoong ngộ cố tri, động phòng hoa chúc dạ, kim bảng đề danh thì (Hạn hán lâu ngày gặp được trận mưa rào, ở nơi đất khách gặp được bạn cũ, đêm động phòng hoa chúc đầy quyến rũ, tuổi trẻ đã được ghi tên trên bảng vàng) hoặc dẫn ra câu trông tin quan nhu trời hạn trông mua (Nguyễn Đình Chiểu: 
Văn tế nghĩa sỹ Cần Giuộc), để gợi mở cho sinh viên cảm nhận và liên hệ với hình thức biểu đạt của lối ví von mang nghĩa tích cực: 如饥似渴 nhu co tư khát, đồng thời tìm ra cách biểu đạt tương đương với 吸取 hấp thủ và 营 养 dinh duõng trong ngữ cảnh của câu văn này trong tiếng Việt. Đáp án tối ưu sẽ là $N h u$ nắng hạn gặp mưa, Tù Bi Hồng đã hăm hở tiếp thu tinh hoa tù trong các tác phẩm hội họa này. Và như vậy, đáp án tối ưu đã thỏa mãn được yêu cầu "bản dịch phải có hai chức năng bao gồm chức năng ý niệm và chức năng liên nhân tương đương với các chức năng này ở bản gốc; và bản dịch cần phải sử dụng các phương tiện ngữ dụng học tương đương để thực hiện các chức năng trên." (Triệu Thu Hằng, 2017).

Trong tiếng Hán cổ đại, cụm bốn chữ thường gọi là tứ tự cách, bao gồm cả dạng cố định và không cố định chiếm ưu thế, tiếng Hán hiện đại ngày nay vẫn được sử dụng nhất là trong diễn đạt viết hàn lâm. Cụm bốn chữ sử dụng đắc địa phát huy được tác dụng lời ít ý nhiều, ngắn gọn súc tích. Trường hợp dùng liền hai, ba cụm còn có tác dụng làm nổi rõ tính tiết tấu, mang lại vẻ đẹp âm nhạc cho câu văn. Tuy nhiên, trong tiếng Việt cụm bốn chữ chỉ thường gặp trong các tác phẩm văn học cổ điển, ngày nay không còn phổ biến nữa. Vì vậy, khi chuyển dịch các cụm từ này từ tiếng Hán sang tiếng Việt, nhiều khi không thể tìm được cụm bốn chữ tương ứng. Mặt khác, có những từ chỉ được sử dụng trong ngữ cảnh này mà không thể phù hợp với ngữ cảnh khác. Do đó, việc căn cứ vào ngữ cảnh cụ thể để xử lý từ ngữ và tìm ra phương thức biểu đạt tương ứng là rất cần thiết. Chẳng hạn như câu 所供货物必须由卖方妥善包装, 适合远洋和长 途内陆运输……耐野蛮装卸 xuất hiện trong văn bản hợp đồng thương mại. Trong câu này, điểm khó thể hiện trong cụm 所供货物 sở cung hóa vật, đặc biệt là cụm 野蛮装卸 dã man trang ta. Với cụm thứ nhất, hư từ 所sở giúp cho động từ đơn âm tiết 供cung chuyển hóa lâm thời thành danh từ làm định ngữ bổ nghĩa cho danh từ song âm tiết 货物 hóa vật, tạo thành cụm bốn chữ, khó có thể chêm thành phần phụ, và cũng khó có thể tìm được cách biểu đạt tương ứng hoàn toàn trong tiếng Việt cả về nội dung và hình thức mà diễn tả hết được ý nghĩa của nó. Để chuyển tải đầy đủ ý nghĩa của cụm từ này sang tiếng Việt, cần phải dùng tới đoản ngữ 11 âm tiết, gần gấp ba so với số âm tiết trong văn bản nguồn, đó là tất cả hàng hóa do bên bán bán cho bên mua. Còn cụm thứ hai, vướng mắc nhất là từ 野蛮 $d \tilde{a}$ man. Đây là từ Việt gốc Hán thường gặp, hầu như tương đương với dã man, man rọ trong mọi trường hợp biểu đạt tương ứng của tiếng Việt. Tuy nhiên, trong trường hợp này, 野蛮 $d a \tilde{a}$ man bổ nghĩa cho装卸trang $t a$ (xếp dỡ), nên không thể chuyển dịch thành xếp dõ dã man được. Như vậy, vai trò của từ Việt gốc Hán ở đây đã bị vô hiệu hóa. Cách biểu đạt tương ứng phải là có thể xếp dõ trong moi truờng hợ. Chính vì vậy, việc hướng dẫn sinh viên xử lý từ ngữ dựa trên ngữ cảnh trong đó có sự kết hợp từ với từ tạo đoản ngữ là vô cùng quan trọng. Đối với những trường hợp khó này, sau khi gợi mở, sinh viên vẫn chưa chắc có thể tìm được đáp án phù hợp nhất, giáo viên cần dựa vào quỹ thời gian cho phép để đưa ra đáp án kịp thời và phân tích thêm để sinh viên lĩnh hội được phương cách chuyển dịch vừa đảm bảo về nghĩa, vừa phù hợp với thói quen biểu đạt của ngôn ngữ đích, được người đọc chấp nhận.

Từ vay mượn tiếng Hán trong tiếng Việt do chịu tác động của quy luật cấu tạo từ tiếng Việt và trải qua quá trình sử dụng của người Việt đã có những thay đổi nhất định về nghĩa, nhiều trường hợp từ Hán Việt tồn tại song song với từ thuần Việt. Chẳng hạn như 梅花是中国的特产名花 trong bài “Hoa của Trung Quốc”. Trong đó, từ 特产 đặc sản trong 
tiếng Hán và đặc sản trong tiếng Việt có sự khác biệt ở chỗ, từ đặc sản trong tiếng Việt đã được thu hẹp nghĩa trong phạm vi ẩm thực. Do đó, giáo viên cần nhấn mạnh điểm khác biệt này để tránh lỗi chuyển dịch câu văn trên thành Hoa mai là loài hoa đặc sản nổi tiếng của Trung Quốc, và tìm ra cách cách biểu đạt tương đương: loài hoa đặc trung/ loài hoa mang màu sắc Trung Quốc/ loài hoa độc đáo... Trong câu này còn có sự hiện diện của 名花danh hoa. Tiếng Việt có các từ 名茶 (danh trà), 名人 (danh nhân), 名画 (danh họa) tồn tại song song với trà nổi tiếng, người nổi tiếng, tác phẩm họi họa nổi tiếng. Tuy nhiên giữa hai cách biểu đạt vẫn có những điểm khác biệt ở sắc thái nghĩa và số lượng âm tiết, nhưng tiếng Việt không có từ danh hoa. Do đó, cần lựa chọn cách biểu đạt thuần Việt hoa nổ $i$ tiếng để phù hợp với thói quen ngôn ngữ của người Việt Nam. Điều đó chứng tỏ, dịch thuật "không chỉ dừng lại ở sự sắp xếp từ vựng và ngữ pháp, mà còn là sự tái thể hiện các giá trị tư tưởng, văn hóa và thông tin chuyên ngành ở một ngôn ngữ khác." (Phan Vũ Tuấn Anh, 2017).

\subsection{Phương pháp xử lý câu}

Ngoài đơn vị từ ngữ ra, trong quá trình dạy dịch, giáo viên cần hướng dẫn sinh viên tiến hành xử lý câu. Trên cơ sở lý thuyết câu là đơn vị giao tiếp cơ bản, nhỏ nhất, việc xử lý câu trong dạy biên dịch cần giúp sinh viên lý giải câu về mặt ngữ pháp, chủ yếu là tiến hành phân tích sơ bộ thành phần câu đối với câu dài, câu khó trong ngôn bản nguồn, từ đó tìm ra các kiểu câu tương ứng, cách biểu đạt tương ứng trong ngôn ngữ đích. Sau đó, thông qua quan sát, so sánh, chỉ ra phương án biểu đạt tối ưu, vừa chuyển tải được đầy đủ thông tin của bản nguồn, vừa tiếp cận được phong cách biểu đạt của người bản ngữ. Trong quá trình hướng dẫn, giáo viên cần thông qua phương thức hỏi đáp bằng hệ thống câu hỏi gợi mở, giúp sinh viên tự quan sát kết hợp với thảo luận nhóm để phát hiện vấn đề. Chẳng hạn như câu 我们 越南河内外语大学//为了促进人才培养方面的国 际交流, //定于 2016 年9月 15 日至9月18日/在本 校大礼堂/ 隆重//举办//汉语教学与研究国际研 讨会, trích trong một bức thư mời.

Quá trình hướng dẫn sinh viên xử lý cấu trúc ngữ pháp của câu này cần tuân thủ các bước sau đây:

+ Yêu cầu sinh viên chỉ ra các thành phần chủ ngữ, vị ngữ chính, trạng ngũ̃, tân ngữ, định ngữ trong câu;

+ Quan sát thành phần trạng ngữ chỉ mục đích, đồng thời xử lý từ ngữ trọng điểm trong câu, gồm 促进xúc tiến tìm ra từ đồng nghĩa, gần nghĩa với 促进 xúc tiến, như 推动 thô $i$ động, 加强 gia cường và chỉ ra các cách biểu đạt tương đương trong tiếng Việt như xúc tiến/ đẩy mạh/ tăng cường; cụm từ 人才培养 方面nhân tài bồi duõng phuơng diện tương đương với phương diện/ mặt/lĩnh vưc/ công tác đào tạo. Trong đó, cần giải thích cho sinh viên nắm được ý nghĩa của từ nhân tài trong tiếng Việt dùng để chỉ những nhân vật xuất chúng, trong ngũ̃ cảnh của câu văn này thì phải chuyển đổi 人才培养 nhân tài bồi duỡng của tiếng Trung Quốc sang đào tạo của tiếng Việt mới đạt được sự tương ứng về nghĩa và thói quen biểu đạt.

+ So sánh vị trí trạng ngũ̃ tiếng Hán và tiếng Việt. Đối với câu văn này, cần hướng dẫn sinh viên đối chiếu với tiếng Việt để tìm ra cách chuyển dịch tối ưu là đưa trạng ngữ chỉ mục đích lên đầu câu, theo thói quen biểu đạt trong tiếng Việt, từ đó nâng lên tầm lý thuyết, rút ra quy tắc chung và sự khác biệt về vị trí trạng ngữ chỉ mục đích trong tiếng Hán và tiếng Việt, sau đó, yêu cầu sinh viên về nhà sưu tầm thêm các ví dụ tương đương, tập chuyển dịch để củng cố kiến thức.

+ Hướng dẫn sinh viên dịch từng thành 
phần câu tiến tới toàn câu. Cuối cùng, giáo viên đưa ra đáp án tối ưu làm chuẩn.

Như vậy, việc xử lý câu phải được tiến hành song song với xử lý từ ngữ xuất hiện trong chính câu dài và khó đó, nhằm giúp cho sinh viên có đầy đủ căn cứ để tiến tới chuyển dịch cả câu văn một cách hoàn chỉnh và có sơ sở lý thuyết.

Ngoài ra, trong quá trình dạy biên dịch, giáo viên cần hướng dẫn sinh viên xác định đúng phong cách văn bản để có phương án chuyển dịch phù hợp. Ví dụ, mở đầu thư mời, tác giả viết “北京大学校长女士:”, giáo viên cần nhắc nhở sinh viên nhớ lại quy cách viết dòng đầu về thông tin người nhận thư (viết ở ô đầu tiên dòng thứ nhất) và vai trò của dấu (:) sau lời xưng hô đầu thư. Tiếp đó là tìm ra cách biểu đạt tương đương trong tiếng Việt (thường có "Kính gửi...” để mở lời). Đối với các văn bản đặc thù như công hàm ngoại giao, hợp đồng kinh tế..., cần đối chiếu hình thức văn bản tiếng Trung Quốc và tiếng Việt để có được bản dịch trọn vẹn, phù hợp với hình thức trình bày của văn bản quy định trong ngôn ngữ đích.

Một ví dụ khác，贵公司于2017年6月12日发 来的询价信已收。谢谢合作! Đoạn văn này gồm hai câu, câu trước tỉnh lược thành phần chủ thể thi hành động tác mà động từ丩 biểu thị và câu sau谢谢合作 tỉnh lược đồng thời cả chủ thể và khách thể của hành động mà động từ 谢谢ta ta (cảm ơn) biểu thị. Tuy nhiên, khi chuyển dịch sang tiếng Việt, câu thứ nhất nhất thiết phải thêm chủ thể của hành động收 thu (nhận): Thu thăm giá gửi ngày 12 tháng 6 năm 2017 của quý công ty chúng tôi đã nhận được hoặc chúng tôi đã nhận được thu thăm giá gửi ngày 12 tháng 6 năm 2017 của quý công ty. Mặt khác, cần thông qua câu hỏi gợi mở giúp sinh viên nhận biết được thành phần trạng ngữ chỉ thời gian trong câu này bổ nghĩa trực tiếp cho động từ 发来phát lai (gửi đến), chứ không phải bổ nghĩa cho động từ 收 thu (nhận) để tránh nhầm lẫn ngày gửi thư và ngày nhận thư như trên thực tế nhiều sinh viên đã mắc lỗi. Riêng câu thứ hai, có ba phương án chuyển dịch như sau:

(1) Xin trân trọng cảm ơn!

(2) Chúng tôi xin trân trọng cảm ơn!

(3) Chúng tôi xin trân trọng cảm ơn sự hợp tác mà quý công ty dành cho chúng tôi.

Với câu này, hình thức biểu đạt giữa tiếng Hán và tiếng Việt có những khác biệt nhất định về phong cách. Việc thêm từ hay bớt từ đã được coi là "chiến lược" trong dịch thuật nhằm đưa ra cách biểu đạt phù hợp với người bản ngữ. Để đạt được mục tiêu đó, đòi hỏi người học phải qua nhiều trải nghiệm và thấm nhuần từng bước. Vì vậy, sau khi hướng dẫn sinh viên tập chuyển dịch, giáo viên cần đưa ra ba phương án trên đây và phân tích ưu, nhược điểm của từng phương án. Trong đó, phương án (1) ngắn gọn, tuy lược bỏ từ 合作 hơp tác nhưng không ảnh hưởng đến tinh thần của thông tin cần truyền đạt, hơn nữa cụm từ xin trân trọng thể hiện cao độ tính lịch sự trong giao tiếp trên thư từ đã giúp cho câu văn tiếng Việt trở nên trang nhã. Phương án (2) thêm chủ ngữ chúng tôi khiến cho câu văn có đầy đủ thành phần hơn phương án (1). Phương án (3) chuyển tải được đầy đủ thông tin, lại có sự xuất hiện của chủ thể và khách thể hành động cảm ơn, kết hợp với sự hỗ trợ của kính ngữ xin trân trọng, do đó tuy dài dòng hơn nhưng không xa rời văn bản nguồn và đảm bảo được tính lịch sự trong giao tiếp. Ba cách biểu đạt này đều thường gặp trong tiếng Việt, vừa phù hợp cảnh huống vừa phù hợp với văn hóa giao tiếp của người Việt.

\section{Một số kiến nghị trong dạy biên dịch cho lưu học sinh Trung Quốc}

Từ những phân tích trên đây, để có thể nâng cao hiệu quả giờ dạy biên dịch Hán Việt 
cho lưu học sinh Trung Quốc, giáo viên cần tuân thủ các nguyên tắc dạy học cũng như các bước giảng và luyện, trước hết là rèn luyện cho sinh viên kỹ năng lí giải văn bản, coi đó là cơ sở để tiến hành dịch.

Giáo viên cần làm chủ bài giảng, trong quá trình soạn giáo án, đưa ra hệ thống câu hỏi gợi mở dẫn dắt người học xử lý từ ngữ, câu, đoạn và cả văn bản hoàn chỉnh, lấy câu làm đơn vị dịch nhỏ nhất. Trong điều kiện thiết bị cho phép, cần soạn giáo án điện tử để có thể sử dụng đa phương tiện vào thực tiễn dạy học để kích thích đồng thời các giác quan tham gia vào giờ học, thông qua hình ảnh trực quan khi trình chiếu các mẫu câu, mỗi thành phần câu được thể hiện bằng một màu sắc hoặc kiểu chữ riêng, đó cũng là một trong những thủ pháp để tạo hứng thú cho sinh viên.

Tận dụng thành quả đối chiếu ngôn ngữ vào dạy học dịch, gồm đối chiếu ngôn ngữ đích với tiếng mẹ đẻ, đối chiếu trong bản thể ngôn ngữ văn bản nguồn và bản thể ngôn ngữ đích, nhằm tránh được sự chuyển di tiêu cực và phát huy sự chuyển di tích cực từ tiếng mẹ đẻ sang ngôn ngữ đích cũng như giữa các điểm ngôn ngữ tương quan trong bản thân ngôn ngữ đích.

Tôn trọng tính chấp nhận được của giao tiếp ngôn ngữ, khuyến khích người học tham gia vào giờ học, tránh áp lực tâm lý, từng bước nâng cao năng lực biểu đạt của người học.

Vận dụng thích đáng kiến thức lí luận ngôn ngữ, lí luận dịch vào thực tiễn dạy học dịch để người học từ "tri kỳ nhiên" tiến tới "tri kỳ sở dĩ nhiên", tức là từ chỗ nhận thức được "nó như thế nào" tiến tới hiểu được "vì sao nó lại như thế". Từ đó có thể đưa ra đáp án tối ưu và có cơ sở khoa học. Việc kết hợp lý luận với thực hành cần quán triệt tinh thần tinh giảng, đa luyện, lấy người học làm trung tâm và giáo viên là người tổ chức, hướng đạo hoạt động học tập. Song song với hoạt động cá nhân cần kết hợp với thảo luận nhóm và chú ý đến tính hợp lí của việc phân chia nhóm học tập, nhằm phát huy hiệu quả của tính tương tác giữa các thành viên trong nhóm.

Ngoài ra, trong quá trình dạy học, cần chú ý trau dồi củng cố kiến thức nền về ngôn ngữ, văn hóa cũng như các kiến thức về từ vựng, ngữ pháp cho sinh viên trên tinh thần "ôn cố tri tân" (ôn cũ biết mới), đồng thời tạo nền tảng cho việc nâng cao năng lực tiếp thu bài giảng và từng bước cải thiện chất lượng lời dịch của sinh viên.

\section{Lò̀i kết}

Cùng với quá trình hội nhập quốc tế, ngày càng nhiều sinh viên Trung Quốc sang Việt Nam học tiếng Việt, công tác nghiên cứu về đối dịch Hán Việt và giảng dạy dịch nói chung, nhất là dạy dịch cho lưu học sinh Trung Quốc càng có ý nghĩa quan trọng trong việc thúc đẩy công tác đào tạo và nâng cao hiệu quả dạy học. Dạy dịch cho lưu học sinh Trung Quốc trước hết phải quán triệt các nguyên tắc dạy học ngoại ngữ nói chung, nhất là nguyên tắc tinh giảng đa luyện và coi người học làm trung tâm, giáo viên là người tổ chức hoạt động dạy học. Trên cơ sở đó hướng dẫn sinh viên tìm hiểu, lý giải văn bản nguồn, xử lý từ và câu, lấy câu làm đơn vị cơ bản để tiến hành dạy học dịch. Việc xử lý câu và từ cần được đặt trong ngữ cảnh, cụ thể là câu hoặc đoạn văn trên dưới, có khi còn là sự kết hợp từ thành cụm từ. Đồng thời tận dụng thành quả so sánh đối chiếu Hán Việt để tranh thủ sự chuyển di tích cực và tránh ảnh hưởng tiêu cực của tiếng mẹ đẻ sang ngôn ngữ đích. Việc sử dụng hợp lý các phương tiện dạy học hiện đại vào thực tiễn nhằm phát huy vai trò của các giác quan, nhất là nghe và nhìn của sinh viên kết hợp với việc biên soạn giáo án điện tử, xây dựng hệ thống câu hỏi gợi mở cũng góp phần to lớn vào việc nâng cao hiệu quả dạy học dịch nói 
chung và dạy học biên dịch Hán Việt cho lưu học sinh Trung Quốc ở Việt Nam nói riêng.

\section{Tài liệu tham khảo}

\section{Tiếng Việt}

Phan Vũ Tuấn Anh (2017). Một số kinh nghiệm giảng dạy môn dịch viết tiếng Trung chuyên ngành quan hệ quốc tế. Kỷ yếu Hội thảo khoa học quốc gia. Nghiên cúu và giảng dạy Ngoại ngũu, Ngôn ngũ và Quốc tế học tại Việt Nam, Nxb ĐHQGHN, 81- 88.

Triệu Thu Hằng (2017). Mô hình chức năng - dụng học trong đánh giá chất lượng bản dịch văn học: Từ lý thuyết tới thực tiễn áp dụng. Nghiên cưu Nước ngoài, 33(4), 91- 100.
Đinh Hồng Vân (2016). Phân tích thông tin trong dịch ngôn bản. Kỷ yếu Hội thảo khoa học quốc gia. Nghiên cứu và giảng dạy Ngoại ngũu, Ngôn ngũ và Quốc tế học tại Việt Nam. Nxb ĐHQGHN, 395- 406.

\section{Tiếng Trung Quốc}

黄勇民（2010）翻译教学与研究, 复旦大学出版社 李宝嘉、唐志超 (2001) 现代汉语规范词典, 吉林 大学出版社, 284

叶苗（1998）关于 “语用翻译学” 的思考, 中国翻 译, 第5 期, 13

胡悦芝 (2013) 从关联理论探讨中国对外国宣传资 料的翻译, 文艺生活文海艺苑第7期; 龙源期刊 网 http://www.qikan.com.cn

\title{
A SKETCH ABOUT TRANSLATION AND CHINESE- VIETNAMESE TRANSLATION TEACHING METHODS FOR CHINESE STUDENTS IN VIETNAM
}

\author{
Pham Ngoc Ham \\ VNU University of Languages and International Studies, \\ Pham Van Dong, Cau Giay, Hanoi, Vietnam
}

\begin{abstract}
Translation can be regarded as one of language skills that requires teachers and students to use the knowledge related to various aspects simultaneously, especially vocabulary and grammar aspects as well as intercultural knowledge in an effort to discover the equivalents between the target and the source language. Based on an overview of some translation theories and translation teaching methodologies, coupled with the actual practice of teaching traslation for Chinese students at some Vietnam's universitites, the article uses such methods as analysis, comparison and contrast to disscuss the methods for addressing the problems concerning words and sentences in translation, thus putting forward some proposals so as to improve teaching Chinese - Vietnamese translation for Chinese students in Vietnam.
\end{abstract}

Keywords: Chinese - Vietnamese translation, teaching, Chinese overseas students, proposal 